\title{
A Review of Vitamin D in Spinal Surgery: Deficiency Screening, Treatment, and Outcomes
}

\author{
BENJAMIN C. MAYO, BA, DUSTIN H. MASSEL, BS, ALEM YACOB, MD, ANKUR S. NARAIN, BA, \\ FADY Y. HIJJI, BS, NATHANIEL W. JENKINS, MS, JAMES M. PARRISH, MPH, KRISHNA D. MODI, BS, \\ WILLIAM W. LONG, BA, NADIA M. HRYNEWYCZ, BS, THOMAS S. BRUNDAGE, BS, KERN SINGH, MD \\ Department of Orthopaedic Surgery, Rush University Medical Center, Chicago, Illinois
}

\begin{abstract}
In this review, we discuss the demonstrated value of vitamin $\mathrm{D}$ in bone maintenance, fracture resistance, spinal health, and spine surgery outcomes. Despite this, the effect of vitamin D levels in spine surgery has not been well described. Through this review of literature, several conclusions were drawn. First, despite the fact that a high number of spine surgery patients are vitamin D deficient, screening is not commonly performed. Second, adequate vitamin D levels will not be achieved in a majority of these patients without supplementation. Last, inadequate vitamin $\mathrm{D}$ levels may increase the risk of pseudarthrosis. Given these findings, we suggest that many patients undergoing spinal surgery could be treated with vitamin D supplementation prior to surgery without the need for confirmatory testing for vitamin $\mathrm{D}$ deficiency. This is a more cost-effective method than screening all patients. However, future randomized trials and cost-effectiveness analyses are needed to determine the ultimate effects of vitamin D supplementation on clinical morbidity and surgical outcomes.
\end{abstract}

Other \& Special Categories

Keywords: vitamin D, spinal surgery, outcomes, 25-hydroxyvitamin D, fusion

\section{INTRODUCTION}

There is growing evidence that suggests vitamin $\mathrm{D}$ is a more critical component of maintaining overall health than previously understood. In composing this review, we found that supplementation of vitamin $\mathrm{D}$ has demonstrated to be protective against chronic diseases such as cancer, diabetes, osteoarthritis, and cardiovascular disease, ${ }^{1-3}$ improve immunological function, ${ }^{2}$ decrease all-cause mortality, 4,5 and improve muscle function and balance. $^{6-10}$ Of particular importance to spine surgeons, vitamin $\mathrm{D}$ is an integral part in the regulation of calcium homeostasis and bone health. As prior studies have demonstrated, low bone mineral density is a significant risk factor for vertebral fracture, instrumentation failure, and pseudarthrosis, signifying the fundamental role bone health plays in the fusion process. ${ }^{1-21}$ Until recently, although hypovitaminosis D (the accepted term for insufficient or deficient levels of vitamin D) was significantly associated with low bone mineral density, ${ }^{22-24}$ the effect of vitamin D levels on outcomes following spinal fusion were not well studied. Within the past several years, literature has indicated that patients' bone and disc health as well as spinal fusion outcomes all may benefit from correcting their vitamin D levels. ${ }^{25}$

\section{Physiology}

Vitamin D is acquired through dietary sources and supplements, as well as exposure to sunlight. The initial form created or ingested in the body is vitamin $\mathrm{D}_{3}$, which must be hydroxylated in the liver to 25 -hydroxyvitamin $\mathrm{D}$, or $25(\mathrm{OH}) \mathrm{D}$, the major circulating form of vitamin D. ${ }^{26}$ Analysis of $25(\mathrm{OH}) \mathrm{D}$ levels in the blood is the universally accepted method to determine overall vitamin D status. $^{7,27-29}$ Inactive $25(\mathrm{OH}) \mathrm{D}$ is converted to the active form 1,25-dihydroxyvitamin $\mathrm{D}$ primarily in the kidney, though other organs contribute minimally. Conversion to 1,25-dihydroxyvitamin $\mathrm{D}$ is a complex process regulated by parathyroid hormone (PTH), calcium, and phosphate levels, the details of which are not salient to the purpose of this article. In addition to regulating calcium and phosphorus absorption in the intestines, 1,25-dihydroxyvitamin $\mathrm{D}$ is crucial in bone turnover and fracture healing 
through stimulating osteoblasts to synthesize new bone matrix proteins. ${ }^{30}$

\section{Screening}

A survey study by Dipaola et $\mathrm{al}^{31}$ reported on spine surgeon attitudes toward osteoporosis and osteomalacia screening. The authors reported that only $12 \%$ of surgeons obtain a metabolic bone laboratory panel before performing an instrumented fusion on a patient with suspected osteoporosis. In addition, only $20 \%$ of surgeons requested blood testing during the work-up of pseudarthrosis. In contrast, $44 \%$ of surgeons will obtain a dual-energy x-ray absorptiometry (DEXA) scan when suspecting osteoporosis prior to instrumented fusion, whereas $19 \%$ of surgeons will obtain a DEXA scan when assessing pseudarthrosis. When questioned regarding their rationale for not screening, $33 \%$ of all surgeons reported the information obtained would not affect their management, and $24 \%$ reported the lab results would not change the patient's degree of osteoporosis. It is interesting that neurosurgeons were significantly more likely than orthopedic surgeons to obtain these laboratory tests during their work-up (32\% versus $15 \%)$.

There is significant debate regarding the appropriate screening protocol for vitamin D deficiency. Whereas some believe that vitamin D deficiency screening should be performed on all orthopedic patients, ${ }^{32,33}$ others have advocated an algorithmic approach to screen only those at risk. ${ }^{34-36}$ Women are at greater risk for vitamin $\mathrm{D}$ deficiency than men; other commonly considered risk factors are obesity, diabetes mellitus, older age, and reduced sunlight exposure. ${ }^{37-40}$ However, not all research suggests that each of these contribute significantly. Thus, defining parameters for which patients to screen is difficult and may result in vitamin Ddeficient patients not receiving treatment. Thomas et $\mathrm{al}^{29}$ reported that at best, only $68 \%$ of patients who are vitamin $\mathrm{D}$ deficient would be identified using risk factors alone, and the only accurate method is to acquire blood $25(\mathrm{OH}) \mathrm{D}$ levels.

The cost associated with preoperative blood testing may be a deterrent to screening all patients. The 2010 Ontario Health Technology Assessment ${ }^{41}$ reported an average cost of $\$ 51.70$ per 25 -hydroxyvitamin D level and $\$ 77.60$ per 1,25-dihydroxyvitamin D level obtained. These costs resulted in a reported \$21.0 million spent on vitamin D screening in 2008, which increased to $\$ 38.8$ million in 2009. In the United States, the cost of obtaining 25(OH)D levels has been reported at $\$ 52.53$ per test. ${ }^{42}$ Although this is a relatively minor expense compared with the overall cost of surgery, the additional fee associated with screening may be unnecessary in a majority of patients. Furthermore, preoperative screening is inefficient due to the lack of a consistent cutoff for determining acceptable levels. Whereas most agree that $25(\mathrm{OH}) \mathrm{D}$ levels below $20 \mathrm{ng} / \mathrm{mL}$ are deficient, the level for "insufficient" is debated, ranging between 20 and $30 \mathrm{ng} / \mathrm{mL}$. More recently, blood levels above $30 \mathrm{ng} / \mathrm{mL}$ have often been used as the "acceptable" range in published literature. ${ }^{30}$

\section{BACKGROUND AND CLINICAL STUDY}

In other orthopedic fields, low vitamin $\mathrm{D}$ has been associated with a significant risk for fracture, impaired healing, and worse outcomes. A 2016 meta-analysis reported that $70 \%$ of all fracture patients have hypovitaminosis $\mathrm{D}$, with a mean blood level of $19.5 \mathrm{ng} / \mathrm{mL}^{24}$ In addition, reports have indicated that as high as $66 \%$ of nongeriatric fracture patients may have vitamin D levels too low to maintain bone health and that have been associated with delayed fusion and higher rates of nonunion. ${ }^{20,21,43-46}$ One study concluded that $57 \%$ of patients who experienced nonunion after total hip arthroplasty had hypovitaminosis D. ${ }^{14}$ In contrast, a study assessing vitamin D levels in patients undergoing total hip arthroplasty reported similar functional outcomes between patients with low and patients with normal vitamin D levels. ${ }^{47}$

Although being relatively well studied in fracture literature, evidence regarding vitamin $\mathrm{D}$ levels and supplementation in spine surgery is rather limited..$^{30}$ Several studies have assessed vitamin D supplementation on patients with low back pain..$^{43,44,46}$ When assessing the effect of vitamin D on patients with chronic low back pain, one study reported that $95 \%$ of all patients $(n=341)$ and $100 \%$ of patients who were vitamin $\mathrm{D}$ deficient $(\mathrm{n}=299)$ described significant improvement of their pain following supplementation. ${ }^{48}$ Similarly, suboptimal concentrations of vitamin $\mathrm{D}$ have been associated with higher risk of cervical disc herniation. ${ }^{49}$

Despite the high prevalence of vitamin D deficiency, screening is not commonplace in spinal health care. Many patients with musculoskeletal disease have disc degeneration. ${ }^{50}$ Several studies have observed that hypovitaminosis $D^{36,43,51}$ is correlated with increased lower back pain and that 
pain relief can be accompanied by vitamin D supplementation. ${ }^{52,53}$ Furthermore, the active form of vitamin D (1,25-dihydroxyvitamin D) has demonstrated an influence in types I and II collagen. ${ }^{54}$ This same form has also been observed to affect the rate of cellular metabolism within the nucleus. Although some contend that the connection between degenerative spinal diseases and poor outcomes results from vitamin D deficiency, several more recent studies found no association. ${ }^{55,56}$ Also potentially relevant in the care of possible spine surgery patients, vitamin D appears to affect bonefracture healing. Lower vitamin $\mathrm{D}$ levels have been observed to correlate with lower bone densities, delayed rate of fracture healing, and screw loosening among patients who have undergone spine surgery. ${ }^{57}$

More recently investigators have focused on the association that deficient levels of vitamin D may have with patient outcomes following spine surgeries (Table). Several poor outcomes that have been hypothesized include decreased postoperative quality of life, elevated pseudarthrosis risk, and decreased functional neurologic performance. ${ }^{25,58}$ The first spine-surgery-focused prospective study we were able to locate observed not only that vitamin D deficiency was common among patients undergoing surgery for spinal stenosis, but also that postsurgical vitamin D levels correlated with postoperative outcomes such as the Oswestry Disability Index and the EuroQol instrument, a five-dimensional three-level generic measure scores. ${ }^{36}$ In a more recent prospective observational study among 31 cervico-thoraco-lumbar fusion patients, Ravindra et $\mathrm{al}^{58}$ observed that patients with a low level of vitamin $\mathrm{D}$ had a higher (odds ratio $=3.449, P=$ .045 ) nonunion rate, and longer median time duration to postoperative fusion (12 months vs 6 months, $P<.001$ ) was associated with vitamin $\mathrm{D}$ levels. Whereas Ravindra et $\mathrm{al}^{58}$ demonstrated that vitamin $\mathrm{D}$ deficiency approached higher rates of nonunion (assessed by radiographs) 12 months after spinal fusion $(20 \%$ vs $38 \%, P=.063)$, the authors acknowledged that their study may have been underpowered to detect statistical significance.

Other retrospective and case series studies over the past 3 decades have also investigated vitamin $\mathrm{D}$ levels in the setting of spine surgery. ${ }^{43,51,55,61}$ Whereas Schofferman et $\mathrm{al}^{61}$ and Donnally et $\mathrm{al}^{55}$ observed no statistically significant association between vitamin $\mathrm{D}$ levels and pseudarthrosis, other studies have indicated that increased vitamin D levels correlated with improved outcomes. ${ }^{43,51}$ Waikakul et $\mathrm{al}^{43}$ studied lumbar fusion patients who had been given $600 \mathrm{IU} / \mathrm{d}$ of vitamin D for 10 days (or until their levels normalized). The authors observed improved Japanese Orthopaedic Association (7.6 vs $4.2 ; P<.050)$ and visual analog scale scores $(7.7$ vs $1.1 ; P<.001)$ that correlated with vitamin D supplementation. ${ }^{43}$ Similarly, in a study of transforaminal lumbar interbody fusion, $\mathrm{Xu}$ et $\mathrm{al}^{51}$ observed significantly higher rates of lumbar fusion $(95.24 \%$ vs $65.22 \% ; P=.020)$ among patients who received vitamin $\mathrm{D}$ supplementation.

A very common degenerative spinal disease among the elderly, spinal stenosis is associated with nerve impingement that can have etiologies such as ligament hypertrophy and degenerative spurs. ${ }^{35}$ Vitamin D deficiencies are hypothesized to be associated with numerous other poor health statuses among patients who have lumbar spinal stenosis, ${ }^{36}$ including an increased susceptibility to diabetes and cardiovascular comorbidities, ${ }^{62}$ higher bone turnover, ${ }^{63}$ and degraded locomotive ability. ${ }^{36}$ In a 2013 study of 350 patients with lumbar spinal stenosis, Kim et $\mathrm{al}^{35}$ reported that patients with severe back and leg pain were nearly 4 times more likely to suffer from vitamin D deficiency than patients with only mild to moderate pain. Furthermore, the researchers reported that lumbar stenosis was identified in $74.3 \%$ of the patient population in their lumbar stenosis study. They also reported that only 10 of the 350 patients within their study population had normal levels of vitamin D.

\section{TREATMENT CONSIDERATIONS}

Supplementation with vitamin $\mathrm{D}$ has been shown to significantly improve blood levels of $25(\mathrm{OH}) \mathrm{D}^{24,62}$ When hypovitaminosis $\mathrm{D}$ is diagnosed, current treatment guidelines suggest a loading regimen of 50000 IU vitamin D weekly, or 6000 IU daily, for 2 months. Following this loading phase, maintenance therapy of 1500 to 2000 IU/d should be continued. ${ }^{28}$ Deficiencies can typically be corrected in 6 to 12 weeks, leading to stabilization of bone turnover. ${ }^{31}$ Given that the optimum blood level for vitamin D remains unclear, the recommended daily vitamin $\mathrm{D}$ necessary to achieve adequate supplementation is also disputed. The Institute of Medicine ${ }^{65}$ recommends 600 IU of vitamin $\mathrm{D}$ per day for those less than 70 years old and $800 \mathrm{IU}$ for those over 70 years old. However, 


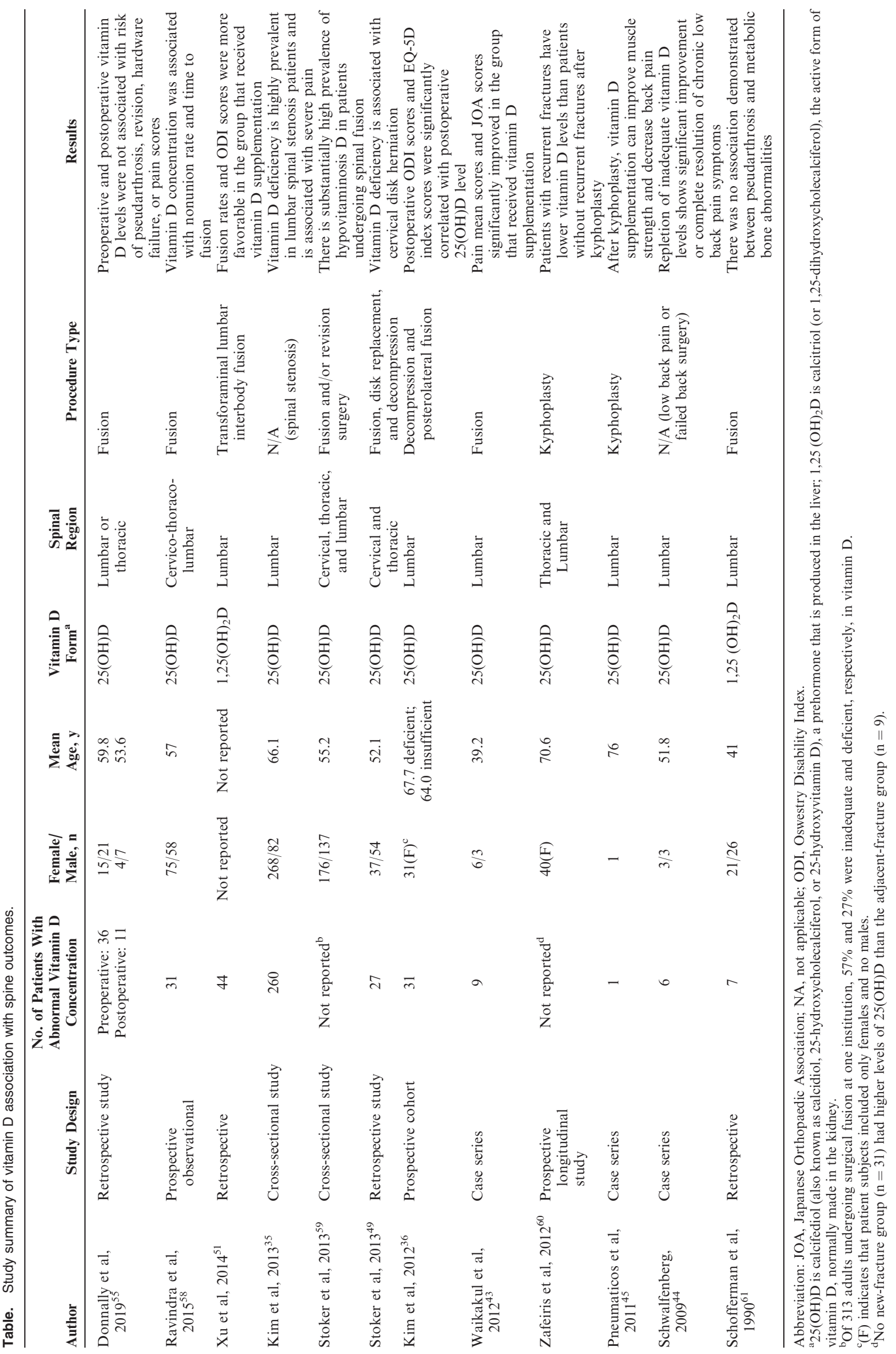


several studies have suggested the recommended dietary allowance is not adequate to achieve satisfactory $25(\mathrm{OH}) \mathrm{D}$ blood levels, and consuming 700 to 2000 IU may be necessary to maintain blood levels greater than $30 \mathrm{ng} / \mathrm{mL}^{7,28,29,66-73}$

This uncertainty in treatment dosing is highlighted in a study surveying orthopedic surgeons on the treatment of hypovitaminosis D. The authors ${ }^{74}$ reported that greater than 45 different vitamin D dosing regimens were prescribed to fracture patients, depending on the population. In addition, the authors concluded that many orthopedic surgeons believe that fracture healing may be improved by vitamin D supplementation but frequently do not prescribe such treatment to their patients.

Although vitamin D supplementation is not commonplace, a higher number of orthopedic surgeons prescribe vitamin D than test for insufficiency. ${ }^{74}$ With all other factors being equal, vitamin D supplementation is significantly less expensive than ordering $25(\mathrm{OH}) \mathrm{D}$ values, with reported costs between $\$ 0.21$ to $\$ 1.46$ per week. ${ }^{58}$ Given the extremely high rate of vitamin D deficiency previously reported, it may be more cost effective, if time permits, to treat the deficiency rather than to test and then treat.

Whereas the morbidity associated with vitamin D supplementation appears relatively low, the decision to offer this treatment will likely need to be made between the patient and surgeon on a case-by-case basis. Although rare, there are risks of vitamin D toxicity with oversupplementation. The Institute of Medicine ${ }^{65}$ reports that $25(\mathrm{OH}) \mathrm{D}$ blood levels of 50 to $60 \mathrm{ng} / \mathrm{mL}$ may put the patient at risk and should be avoided; similarly, they recommend a daily intake no higher than $4000 \mathrm{IU}$ to avoid toxicity. The most common symptoms of acute intoxication are nausea, vomiting, constipation, and polyuria. Once recognized, there are many different treatment options available, depending on the severity and acuity of the toxicity.

Likewise, a flat recommendation to treat all patients with preoperative vitamin $\mathrm{D}$, although seemingly inexpensive, can be complicated by numerous other implicit costs if the decision for surgery is not well planned. For example, the 6- to 8 -week duration that is often required for loading patients with a weekly dose of vitamin D may have significant consequences with patient and clinical morbidity. Treating patients with extensive preoperative vitamin $\mathrm{D}$ therapy might be discouraged among those who are enduring high levels of ongoing pain, disability, or other costly therapies. The clinical cost of delaying surgery can also have costly repercussions in terms of other pharmaceutical therapies required to control pain, lost patient wages, and a possible adverse effect of an extended duration of symptoms.

Unfortunately, few studies have assessed the effect of vitamin D supplementation or postoperative vitamin $\mathrm{D}$ levels on spinal fusion rates in humans. A study by Lawrence at $\mathrm{al}^{75}$ examined the effect of daily parathyroid hormone (PTH) supplementation on rats undergoing spinal fusion. Though statistical significance was not reached, rats that received daily $\mathrm{PTH}$ demonstrated higher rates of fusion than rats who did not receive $\mathrm{PTH}^{75}$ Whereas PTH does not replicate vitamin D supplementation, their actions and biochemical functions are similar. Similarly, Metzger et $\mathrm{al}^{57}$ assessed fusion rates in rats with varying levels of vitamin D; rats with increased vitamin D supplementation experienced higher fusion rates, bone volume, and bone density. It is interesting that one study demonstrated that vitamin $\mathrm{D}$ levels improve in the weeks to months following surgery even without supplementation, significantly so in those who were deficient preoperatively. ${ }^{36}$ The authors hypothesized that the increased levels were likely a result of increased physical function achieved following surgery.

\section{CONCLUSIONS}

This review of current literature regarding vitamin D levels and spine surgery has several salient points for spinal surgeons to consider. Despite a high number of vitamin D-deficient spine surgery patients, screening for hypovitaminosis $\mathrm{D}$ is not commonly performed. Second, adequate levels of vitamin $\mathrm{D}$ will not be achieved in a majority of patients with a deficiency without supplementation to their regular diet. Last, inadequate vitamin D levels may increase the risk of pseudarthrosis following spinal surgery.

Given the current literature, we advise against obtaining routine vitamin $\mathrm{D}$ levels in patients undergoing spinal surgery. Although it is true that a high number of patients undergoing spinal fusion will be vitamin $\mathrm{D}$ deficient, the utility of assessing the value before surgery is limited. By identifying patients with low vitamin D preoperatively, patients may be treated with supplementation and potentially minimize complications. However, testing 
vitamin D levels is costly and often unwarranted in many patients. A potentially more appropriate approach would be to preemptively treat all patients with vitamin $\mathrm{D}$ and continue supplementation until arthrodesis has been confirmed. Although identifying which patients will actually benefit from supplementation has its merits, from a practical standpoint there is limited benefit.

With further cost analysis, we believe there is good reason to consider treating the majority patients given the relatively low up-front expense. The average cost of a revision surgery for pseudarthrosis is $\$ 28069$. With vitamin D supplementation, it may be possible for a surgeon to effectively reduce pseudarthrosis rates and complication expenses at a fraction of the cost. ${ }^{76}$ Whereas many spine surgeons may be underestimating the effect of vitamin $\mathrm{D}$ as a cost-effective method for improving spinal fusion, ${ }^{57}$ a flat recommendation to treat all patients must also be weighed against other costs associated with patient and clinical morbidity. Likewise, although it does not appear to be cost-effective to screen all patients, if a patient who is prescribed vitamin D presents with pseudarthrosis, it may be beneficial to check $25(\mathrm{OH}) \mathrm{D}$ values to determine whether vitamin D may still be contributing or further work-up is required.

While these recommendations, high-quality research such as randomized trials and rigorous costeffectiveness analysis are needed to make more definitive claims. Whereas the current literature may suggest vitamin $\mathrm{D}$ is likely associated with positive surgical outcomes, conclusive studies comparing the effects of vitamin D treatment are necessary to determine whether supplementation is beneficial, and if so, what dosing is optimal. ${ }^{58}$

\section{REFERENCES}

1. Grant WB. An estimate of premature cancer mortality in the US due to inadequate doses of solar ultraviolet-B radiation. Cancer. 2002;94(6):1867-1875.

2. Hayes CE, Nashold FE, Spach KM, Pedersen LB. The immunological functions of the vitamin D endocrine system. Cell Mol Biol (Noisy-le-grand). 2003;49(2):277-300.

3. Holick MF. Vitamin D deficiency. $N$ Engl $J$ Med. 2007;357(3):266-281.

4. Thomas GN, ó Hartaigh B, Bosch JA, et al. Vitamin D levels predict all-cause and cardiovascular disease mortality in subjects with the metabolic syndrome: the Ludwigshafen Risk and Cardiovascular Health (LURIC) Study. Diabetes Care. 2012;35(5):1158-1164.

5. Autier P, Gandini S. Vitamin D supplementation and total mortality: a meta-analysis of randomized controlled trials. Arch Intern Med. 2007;167(16):1730-1737.

6. Pfeifer M, Begerow B, Minne HW, Abrams C, Nachtigall D, Hansen C. Effects of a short-term vitamin D and calcium supplementation on body sway and secondary hyperparathyroidism in elderly women. $J$ Bone Miner Res. 2000;15(6):11131118.

7. Bischoff-Ferrari HA, Dawson-Hughes B, Orav EJ, et al. Monthly high-dose vitamin D treatment for the prevention of functional decline: a randomized clinical trial. JAMA Intern Med. 2016;176(2):175-183.

8. Annweiler C, Schott AM, Berrut G, Fantino B, Beauchet O. Vitamin D-related changes in physical performance: a systematic review. J Nutr Health Aging. 2009;13(10):893-898.

9. Bischoff HA, Stahelin HB, Dick W, et al. Effects of vitamin D and calcium supplementation on falls: a randomized controlled trial. J Bone Miner Res. 2003;18(2):343-351.

10. Bischoff-Ferrari HA, Dawson-Hughes B, Staehelin HB, et al. Fall prevention with supplemental and active forms of vitamin D: a meta-analysis of randomised controlled trials. BMJ. 2009;339:b3692.

11. Yagi $M$, King AB, Boachie-Adjei O. Incidence, risk factors, and natural course of proximal junctional kyphosis: surgical outcomes review of adult idiopathic scoliosis. Minimum 5 years of follow-up. Spine (Phila Pa 1976). 2012;37(17):1479-1489.

12. Kalb S, Mahan MA, Elhadi AM, et al. Pharmacophysiology of bone and spinal fusion. Spine J. 2013;13(10):13591369.

13. Okuyama K, Abe E, Suzuki T, Tamura Y, Chiba M, Sato K. Influence of bone mineral density on pedicle screw fixation: a study of pedicle screw fixation augmenting posterior lumbar interbody fusion in elderly patients. Spine $J$. 2001;1(6):402-407.

14. Brinker MR, O'Connor DP, Monla YT, Earthman TP. Metabolic and endocrine abnormalities in patients with nonunions. J Orthop Trauma. 2007;21(8):557-570.

15. Dvorak MF, Pitzen T, Zhu Q, Gordon JD, Fisher CG, Oxland TR. Anterior cervical plate fixation: a biomechanical study to evaluate the effects of plate design, endplate preparation, and bone mineral density. Spine (Phila $\mathrm{Pa}$ 1976). 2005;30(3):294-301.

16. Reitman CA, Nguyen L, Fogel GR. Biomechanical evaluation of relationship of screw pullout strength, insertional torque, and bone mineral density in the cervical spine. $J$ Spinal Disord Tech. 2004;17(4):306-311.

17. Seller K, Wahl D, Wild A, Krauspe R, Schneider E, Linke B. Pullout strength of anterior spinal instrumentation: a product comparison of seven screws in calf vertebral bodies. Eur Spine J. 2007;16(7):1047-1054.

18. LeBoff MS, Hawkes WG, Glowacki J, Yu-Yahiro J, Hurwitz S, Magaziner J. Vitamin D-deficiency and postfracture changes in lower extremity function and falls in women with hip fractures. Osteoporos Int. 2008;19(9):1283-1290.

19. Kocjan T, Tan TM, Conway GS, Prelevic G. Vitamin D status in patients with osteopenia or osteoporosis - an audit of an endocrine clinic. Int J Vitam Nutr Res. 2006;76(5):307-313.

20. Robertson DS, Jenkins T, Murtha YM, et al. Effectiveness of Vitamin D therapy in orthopaedic trauma patients. $J$ Orthop Trauma. 2015;29(11):e451-e453.

21. Zellner BS, Dawson JR, Reichel LM, et al. Prospective 
nutritional analysis of a diverse trauma population demonstrates substantial hypovitaminosis D. J Orthop Trauma. 2014;28(9):e210-e215.

22. Mezquita-Raya P, Munoz-Torres M, Luna JD, et al. Relation between vitamin D insufficiency, bone density, and bone metabolism in healthy postmenopausal women. $J$ Bone Miner Res. 2001;16(8):1408-1415.

23. Harwood RH, Sahota O, Gaynor K, Masud T, Hosking DJ; Nottingham Neck of Femur (NONOF) Study. A randomised, controlled comparison of different calcium and vitamin D supplementation regimens in elderly women after hip fracture: the Nottingham Neck of Femur (NONOF) Study. Age Ageing. 2004;33(1):45-51.

24. Sprague S, Petrisor B, Scott T, et al. What is the role of vitamin $\mathrm{D}$ supplementation in acute fracture patients? A systematic review and meta-analysis of the prevalence of hypovitaminosis D and supplementation efficacy. J Orthop Trauma. 2016;30(2):53-63.

25. Kerezoudis P, Rinaldo L, Drazin D, et al. Association between vitamin $\mathrm{D}$ deficiency and outcomes following spinal fusion surgery: a systematic review. World Neurosurg. 2016;95:71-76.

26. Patton CM, Powell AP, Patel AA. Vitamin D in orthopaedics. J Am Acad Orthop Surg. 2012;20(3):123-129.

27. Binkley N, Novotny R, Krueger D, et al. Low vitamin D status despite abundant sun exposure. J Clin Endocrinol Metab. 2007;92(6):2130-2135.

28. Holick MF, Binkley NC, Bischoff-Ferrari HA, et al. Evaluation, treatment, and prevention of vitamin D deficiency: an Endocrine Society clinical practice guideline. $J$ Clin Endocrinol Metab. 2011;96(7):1911-1930.

29. Thomas MK, Lloyd-Jones DM, Thadhani RI, et al. Hypovitaminosis D in medical inpatients. $N$ Engl J Med. 1998;338(12):777-783.

30. Rodriguez WJ, Gromelski J. Vitamin D status and spine surgery outcomes. ISRN Orthop. 2013;2013:471695.

31. Dipaola CP, Bible JE, Biswas D, Dipaola M, Grauer JN, Rechtine GR. Survey of spine surgeons on attitudes regarding osteoporosis and osteomalacia screening and treatment for fractures, fusion surgery, and pseudoarthrosis. Spine $J$. 2009;9(7):537-544.

32. de Divitiis O, De Angelis M, Turgut AT. Vitamin D deficiency in spinal surgery: can it compromise the outcome? World Neurosurg. 2015;83(6):1044-1045.

33. Holick MF. Vitamin D deficiency: what a pain it is. Mayo Clin Proc. 2003;78(12):1457-1459.

34. Choma TJ, Rechtine GR, McGuire RA Jr, Brodke DS. Treating the aging spine. $J$ Am Acad Orthop Surg. 2015;23(12):e91-e100.

35. Kim TH, Lee BH, Lee HM, et al. Prevalence of vitamin $\mathrm{D}$ deficiency in patients with lumbar spinal stenosis and its relationship with pain. Pain Physician. 2013;16(2):165-176.

36. Kim TH, Yoon JY, Lee BH, et al. Changes in vitamin D status after surgery in female patients with lumbar spinal stenosis and its clinical significance. Spine. 2012;37(21):E1326E1330.

37. MacLaughlin J, Holick MF. Aging decreases the capacity of human skin to produce vitamin D3. J Clin Invest. 1985;76(4):1536-1538.

38. Saintonge S, Bang H, Gerber LM. Implications of a new definition of vitamin D deficiency in a multiracial US adolescent population: the National Health and Nutrition Examination Survey III. Pediatrics. 2009;123(3):797-803.

39. Yetley EA. Assessing the vitamin D status of the US population. Am J Clin Nutr. 2008;88(2):S558-S564.

40. Ravindra VM, Godzik J, Guan J, et al. Prevalence of vitamin $\mathrm{D}$ deficiency in patients undergoing elective spine surgery: a cross-sectional analysis. World Neurosurg. 2015;83(6):1114-1119.

41. Medical Advisory Secretariat. Clinical utility of vitamin D testing: an evidence-based analysis. Ont Health Technol Assess Ser. 2010;10(2):1-93.

42. Pacis MM, Fortin CN, Zarek SM, Mumford SL, Segars JH. Vitamin D and assisted reproduction: should vitamin D be routinely screened and repleted prior to ART? A systematic review. J Assist Reprod Genet. 2015;32(3):323-335.

43. Waikakul S. Serum 25-hydroxy-calciferol level and failed back surgery syndrome. J Orthop Surg (Hong Kong). 2012;20(1):18-22.

44. Schwalfenberg G. Improvement of chronic back pain or failed back surgery with vitamin D repletion: a case series. $J$ Am Board Fam Med. 2009;22(1):69-74.

45. Pneumaticos SG, Zafeiris CP, Chronopoulos E, Kassi E, Lyritis GP. Vitamin D deficiency resulting to a subsequent vertebral fracture after kyphoplasty. J Musculoskelet Neuronal Interact. 2011;11(1):81-83.

46. Plehwe WE, Carey RP. Spinal surgery and severe vitamin D deficiency. Med J Aust. 2002;176(9):438-439.

47. Lavernia CJ, Villa JM, Iacobelli DA, Rossi MD. Vitamin D insufficiency in patients with THA: prevalence and effects on outcome. Clin Orthop Relat Res. 2014;472(2):681686.

48. Al Faraj S, Al Mutairi K. Vitamin D deficiency and chronic low back pain in Saudi Arabia. Spine (Phila Pa 1976). 2003;28(2):177-179.

49. Stoker GE, Buchowski JM, Chen CT, Kim HJ, Park MS, Riew KD. Hypovitaminosis D and cervical disk herniation among adults undergoing spine surgery. Global Spine $J$. 2013;3(4):231-236.

50. Xu HW, Shen B, Hu T, Zhao WD, Wu DS, Wang SJ. Preoperative vitamin D status and its effects on short-term clinical outcomes in lumbar spine surgery. J Orthop Sci. 2019; S0949-2658(19)30332-X.

51. Xu Y, Zhou M, Liu H, et al. Effect of 1,25dihydroxyvitamin D3 on posterior transforaminal lumbar interbody fusion in patients with osteoporosis and lumbar disc degenerative disease. 2014;28(8):969-972.

52. Englund M, Persson J, Bergström I. Lower pain and higher muscular strength in immigrant women with vitamin D deficiency following vitamin $\mathrm{D}$ treatment. Int $J$ Circumpolar Health. 2017;76(1):1340547.

53. Breidebach JB, Koch EMW, Bornemann R, et al. Low vitamin $\mathrm{D}$ levels affect outcomes of orthopedic spinal surgery: an observational study in clinical practice. Technol Health Care. 2018;26(2):305-317.

54. Colombini A, Lanteri P, Lombardi G, et al. Metabolic effects of vitamin $D$ active metabolites in monolayer and micromass cultures of nucleus pulposus and annulus fibrosus cells isolated from human intervertebral disc. Int J Biochem Cell Biol. 2012;44(6):1019-1030.

55. Donnally CJ 3rd, Sheu JI, Bondar KJ, et al. Is there a correlation between preoperative or postoperative vitamin D 
Levels with pseudarthrosis, hardware failure, and revisions after lumbar spine fusion? World Neurosurg. 2019;130:e431-e437.

56. Heuch I, Heuch I, Hagen K, Mai XM, Langhammer A, Zwart JA. Is there an association between vitamin D status and risk of chronic low back pain? A nested case-control analysis in the Nord-Trondelag Health Study. BMJ Open. 2017;7(11):e018521.

57. Metzger MF, Kanim LE, Zhao L, Robinson ST, Delamarter RB. The relationship between serum vitamin D levels and spinal fusion success: a quantitative analysis. Spine. 2015;40(8):E458-E468.

58. Ravindra VM, Godzik J, Dailey AT, et al. Vitamin D levels and 1-year fusion outcomes in elective spine surgery: a prospective observational study. Spine. 2015;40(19):1536-1541.

59. Stoker GE, Buchowski JM, Bridwell KH, Lenke LG, Riew KD, Zebala LP. Preoperative vitamin D status of adults undergoing surgical spinal fusion. Spine (Phila Pa 1976). 2013;38(6):507-515.

60. Zafeiris CP, Lyritis GP, Papaioannou NA, et al. Hypovitaminosis D as a risk factor of subsequent vertebral fractures after kyphoplasty. Spine J. 2012;12(4):304-312.

61. Schofferman J, Schofferman L, Zucherman J, Hsu K, White A. Metabolic bone disease in lumbar pseudarthrosis. Spine (Phila Pa 1976). 1990;15(7):687-689.

62. Lotan R, Oron A, Anekstein Y, Shalmon E, Mirovsky Y. Lumbar stenosis and systemic diseases: is there any relevance? J Spinal Disord Tech. 2008;21(4):247-251.

63. Lee $\mathrm{BH}$, Moon $\mathrm{SH}$, Kim HJ, Lee HM, Kim TH. Osteoporotic profiles in elderly patients with symptomatic lumbar spinal canal stenosis. Indian J Orthop. 2012;46(3):279284.

64. Whiting SJ, Bonjour JP, Payen FD, Rousseau B. Moderate amounts of vitamin D3 in supplements are effective in raising serum 25-hydroxyvitamin $\mathrm{D}$ from low baseline levels in adults: a systematic review. Nutrients. 2015;7(4):2311-2323.

65. Institute of Medicine (US) Committee to Review Dietary Reference Intakes for Vitamin D and Calcium; Ross AC, Taylor CL, Yaktine AL, et al., editors. Institute of Medicine Dietary Reference Intakes for Calcium and Vitamin D. Washington, DC: National Academies Press; 2010.

66. Glerup H, Mikkelsen K, Poulsen L, et al. Commonly recommended daily intake of vitamin $\mathrm{D}$ is not sufficient if sunlight exposure is limited. J Intern Med. 2000;247(2):260-268.

67. Heaney RP, Dowell MS, Hale CA, Bendich A. Calcium absorption varies within the reference range for serum 25hydroxyvitamin D. J Am Coll Nutr. 2003;22(2):142-146.

68. Hollis BW. Circulating 25-hydroxyvitamin D levels indicative of vitamin D sufficiency: implications for establishing a new effective dietary intake recommendation for vitamin D. $J$ Nutr. 2005;135(2):317-322.
69. Vieth R. Vitamin D supplementation, 25-hydroxyvitamin D concentrations, and safety. Am J Clin Nutr. 1999;69(5):842-856.

70. Vieth R. Why the optimal requirement for Vitamin D3 is probably much higher than what is officially recommended for adults. J Steroid Biochem Mol Biol. 2004;89-90(1-5):575-579.

71. Barger-Lux MJ, Heaney RP, Dowell S, Chen TC, Holick MF. Vitamin D and its major metabolites: serum levels after graded oral dosing in healthy men. Osteoporos Int. 1998;8(3):222-230.

72. Dawson-Hughes B, Heaney RP, Holick MF, Lips P, Meunier PJ, Vieth R. Estimates of optimal vitamin D status. Osteoporos Int. 2005;16(7):713-716.

73. Tangpricha V, Pearce EN, Chen TC, Holick MF. Vitamin D insufficiency among free-living healthy young adults. Am J Med. 2002;112(8):659-662.

74. Sprague S, Bhandari M, Devji T, et al. Prescription of vitamin D to fracture patients: a lack of consensus and evidence. J Orthop Trauma. 2016;30(2):e64-e69.

75. Lawrence JP, Ennis F, White AP, et al. Effect of daily parathyroid hormone (1-34) on lumbar fusion in a rat model. Spine J. 2006;6(4):385-390.

76. Adogwa O, Owens R, Karikari I, et al. Revision lumbar surgery in elderly patients with symptomatic pseudarthrosis, adjacent-segment disease, or same-level recurrent stenosis. Part 2. A cost-effectiveness analysis: clinical article. J Neurosurg Spine. 2013;18(2):147-153.

Disclosures and COI: No funds were received in support of this work. No benefits in any form have been or will be received from any commercial party related directly or indirectly to the subject of this manuscript.

Corresponding Author: Kern Singh, MD, Professor, Department of Orthopaedic Surgery, Rush University Medical Center, 1611 W. Harrison St, Suite 300, Chicago, IL 60612. Phone: (312) $432-$ 2373; Fax: (708) 409-5179; Email: kern.singh@ rushortho.com.

Published 30 June 2020

This manuscript is generously published free of charge by ISASS, the International Society for the Advancement of Spine Surgery. Copyright (C) 2020 ISASS. To see more or order reprints or permissions, see http://ijssurgery.com. 